\title{
Association of optic atrophy and type 1 diabetes: clinical hallmarks for the diagnosis of Wolfram syndrome
}

Associação de atrofia óptica e diabetes tipo 1: marcadores clínicos para o diagnóstico da síndrome de Wolfram

José Luiz Pedroso', Leandro Tavares Lucato2,3, Fernando Kok, Juliana Sallum5, Orlando G. P. Barsottini', Acary Souza Bulle Oliveira ${ }^{1}$

A 25-year-old woman presented with a 3-year history of progressive visual loss. She had type 1 diabetes mellitus (DM1) since 18-year-old. Fundoscopy showed atrophic optic discs (Figure 1). MRI disclosed bilateral optic nerve atrophy (Figure 2). Optic coherence temography demonstrated disease progression (Figure 3). Exome sequencing disclosed two deleterious mutations in WFS gene [the novel variant c.1228_1231delCTCT (p.Leu410Leufs*31) and the already reported mutation ${ }^{1}$ c.472 G>A (p.Glu158Lys)], confirming
Wolfram syndrome (WFS). Full consent was obtained from the patient for the case publication

WFS is a rare autosomal recessive disease characterized by DM1, optic atrophy, deafness, and diabetes insipidus ${ }^{2,3}$. The coexistence of DM1 and optic atrophy suggest WFS but molecular confirmation is mandatory ${ }^{4}$. Besides optic atrophy, MRI findings in WFS may include hyperintense signal in pons and in optic tracts, brainstem atrophy and absence of neurohypophyseal "bright signal" 5 .

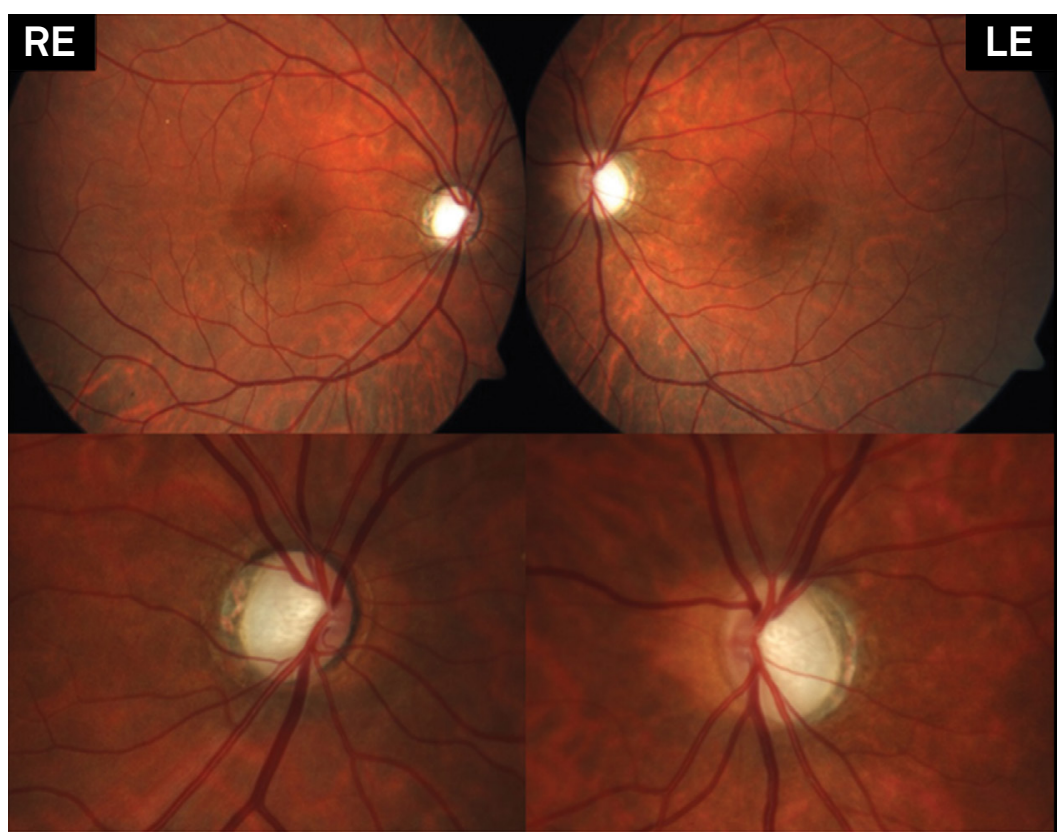

Figure 1. Fundus image discloses marked bilateral atrophic optic discs with temporal pallor.

\footnotetext{
'Universidade Federal de São Paulo, Departamento de Neurologia, Sao Paulo SP, Brazil;

2Universidade de São Paulo, Faculdade de Medicina, Hospital das Clínicas, Departamento de Neuroradiologia, Sao Paulo SP, Brazil; 

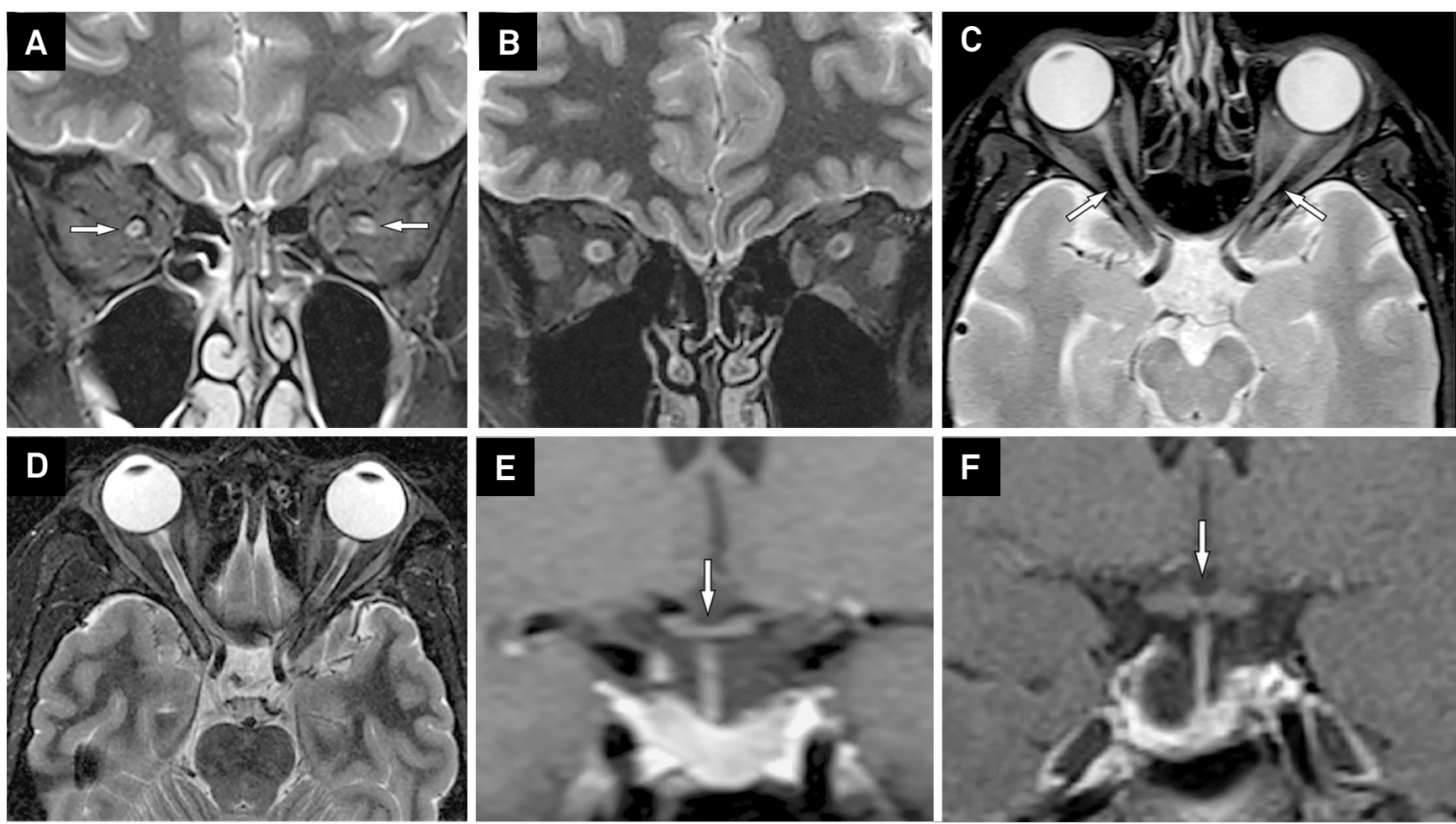

Figure 2. MRI of Wolfram patient (A, C, E) compared with an age-matched healthy subject (B, D, F). Coronal T2-weighted image using fat saturation (A) demonstrates striking hypoplasia of both optic nerves in the orbits (arrows); note the normal appearance in the healthy subject (B). The same sequence in the axial plane shows the same finding in the patient (C - arrows), compared to the normal aspect (D). Optic chiasm is also hypoplastic in Wolfram patient, demonstrated in a coronal post-contrast T1-weighted image ( $E$ - arrow), while a normal optic chiasm is appreciated in the healthy subject ( $F$ - arrow).
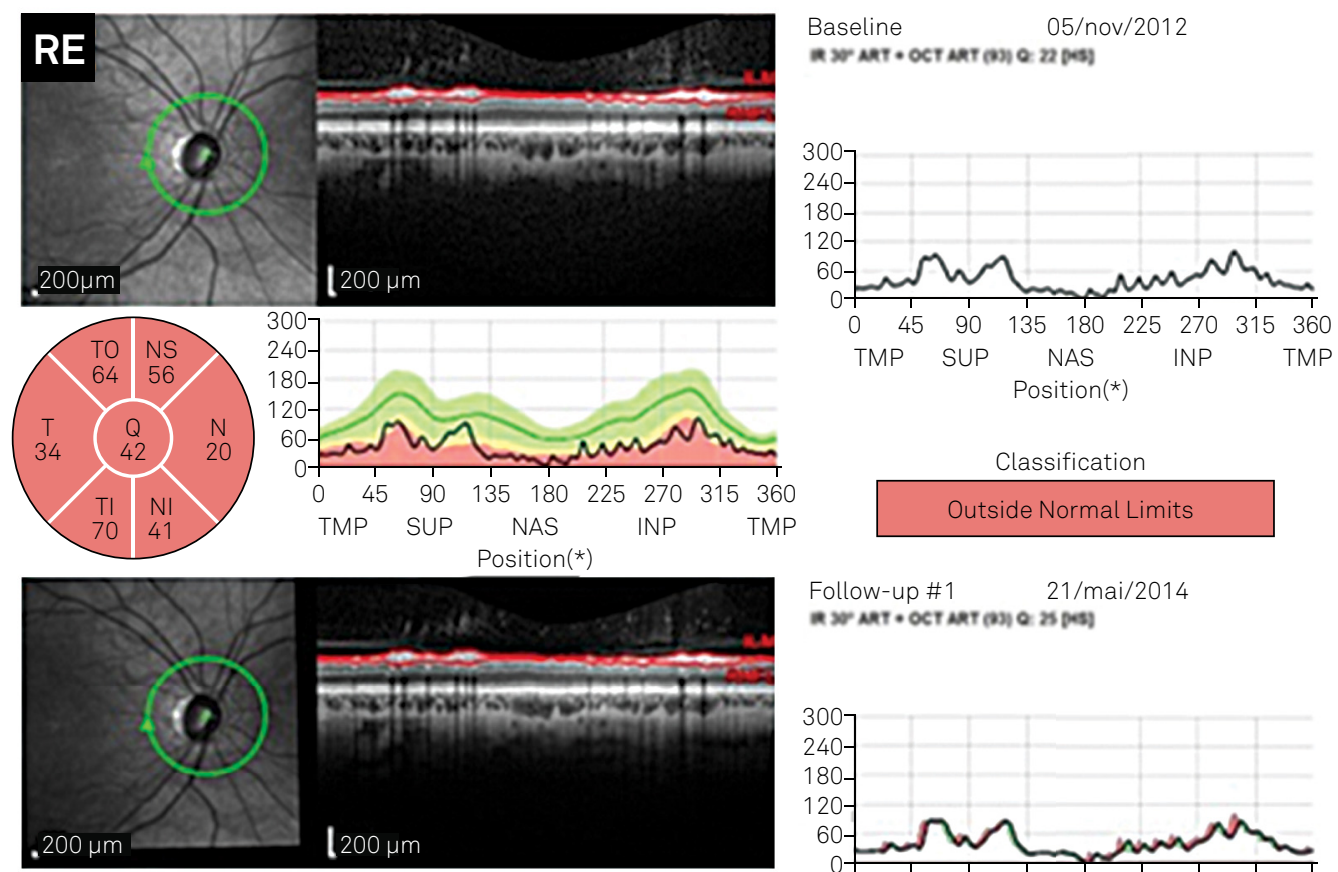

ans ant oct ant ane: as pess
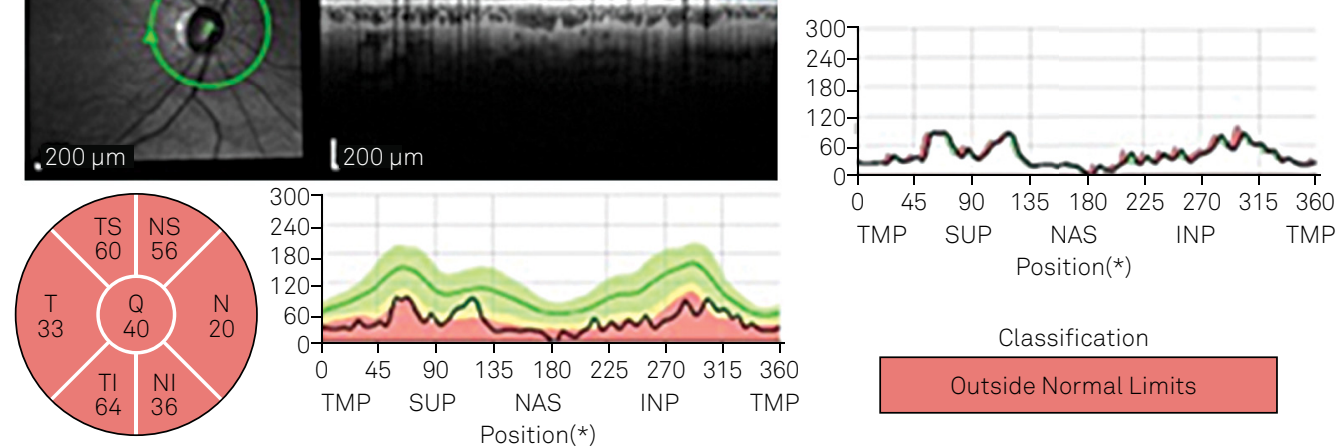

Figure 3. Optic coherence tomography measure around the disc showing thin retina, mainly thin nerve fiber layer performed at two dates (Nov 05th 2012 and May 21st 2014). Comparing both exams one can see progressive decrease on the retina thickness (Continua). 


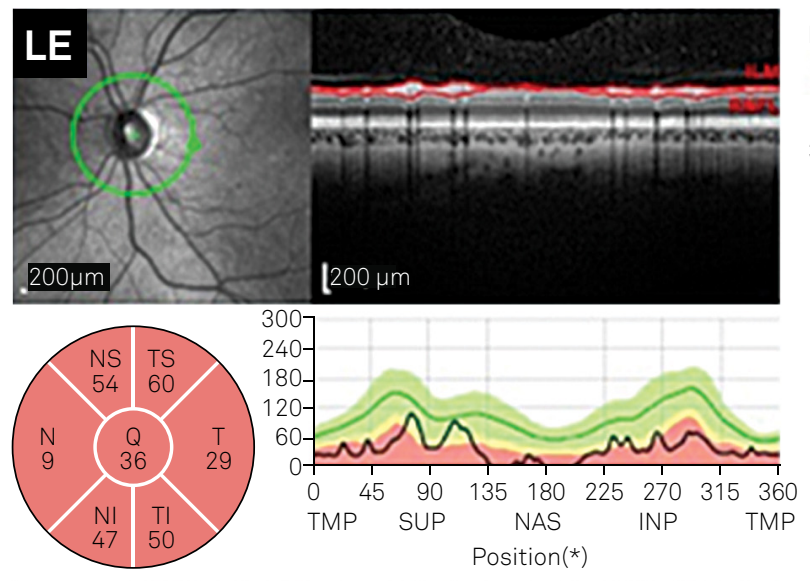

Baseline 05/nov/2012

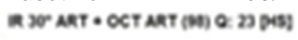

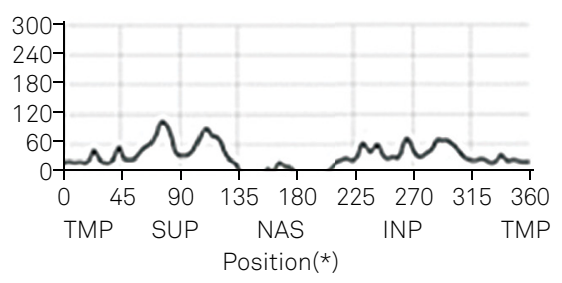

Classification

Outside Normal Limits

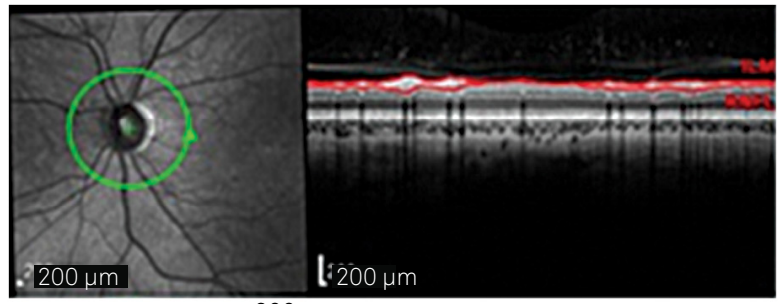

Follow-up \#1 21/mai/2014

a ser a
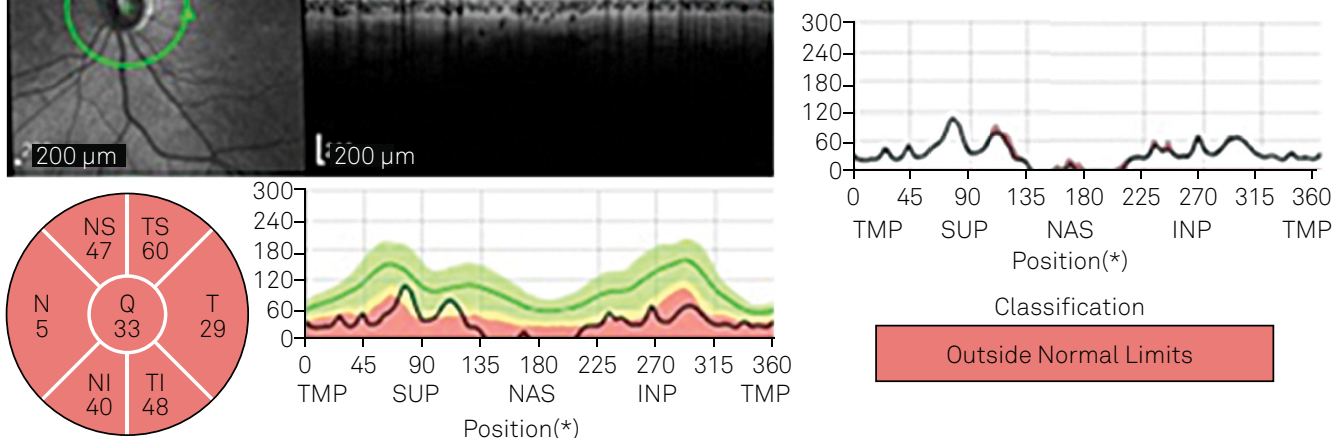

Outside Normal Limits

Figure 3. (Continuação) Optic coherence tomography measure around the disc showing thin retina, mainly thin nerve fiber layer performed at two dates (Nov 05th 2012 and May 21st 2014). Comparing both exams one can see progressive decrease on the retina thickness.

\section{References}

1. Gasparin MR, Crispim F, Paula SL, Freire MBS, Dalbosco IS, Manna TD et al. Identification of novel mutations of the WFS1 gene in Brazilian patients with Wolfram syndrome. Eur J Endocrinol. 2009;160(2):309-16. http://dx.doi.org/10.1530/EJE-08-0698

2. Marshall BA, Permutt MA, Paciorkowski AR, Hoekel J, Karzon R, Wasson J et al. Phenotypic characteristics of early Wolfram syndrome. Orphanet J Rare Dis. 2013;8:64. http://dx.doi.org/10.1186/1750-1172-8-64

3. Zmystowska A, Borowiec M, Fendler W, Jarosz-Chobot P, Myśliwiec M, Szadkowska A et al. The prevalence of Wolfram syndrome in a paediatric population with diabetes. Endokrynol Pol. 2014;65(4):295-7. http://dx.doi.org/10.5603/EP.2014.0040

4. Zmyslowska A, Borowiec M, Fichna P, et al. Delayed recognition of Wolfram syndrome frequently misdiagnosed as type 1 diabetes with early chronic complications. Exp Clin Endocrinol Diabetes. 2014;122(1):35-8. http://dx.doi.org/10.1055/s-0033-1357160

5. Gocmen R, Guler E. Teaching Neuro/mages: MRI of brain findings of Wolfram (DIDMOAD) syndrome. Neurology. 2014;83(24):e213-4. http://dx.doi.org/10.1212/WNL.0000000000001082 